\title{
Nanostructured lipid carriers as a novel tool to deliver sclareol: physicochemical characterisation and evaluation in human cancer cell lines
}

\author{
Gabriel Silva Marques Borges', Pedro Henrique Dias Moura Prazeres², \\ Ângelo Malachias de Souza ${ }^{3}$, Maria Irene Yoshida ${ }^{4}$, \\ José Mario Carneiro Vilela ${ }^{5}$, Aline Teixeira Maciel e Silva ${ }^{1}$, \\ Mariana Silva Oliveira1, Dawidson Assis Gomes ${ }^{6}$, Margareth Spangler Andrade \\ Elaine Maria de Souza-Fagundes ${ }^{2}$, Lucas Antônio Miranda Ferreira ${ }^{\circledR 1}$ \\ ${ }^{1}$ Department of Pharmaceutics, Faculty of Pharmacy, Federal University of Minas Gerais, \\ Belo Horizonte, Brazil, ${ }^{2}$ Department of Physiology and Biophysics, Biological Sciences \\ Institute, Federal University of Minas Gerais, Belo Horizonte, Brazil, ${ }^{3}$ Department of \\ Physics, Institute of Exact Sciences, Federal University of Minas Gerais, Belo Horizonte, \\ Brazil, ${ }^{4}$ Department of Chemistry, Institute of Exact Sciences, Federal University of Minas \\ Gerais, Belo Horizonte, Brazil, ${ }^{5}$ Technology and Innovation Center, Industrial Learning \\ National Service, Belo Horizonte, Brazil, ${ }^{6}$ Department of Biochemistry and Immunology, \\ Biological Sciences Institute, Federal University of Minas Gerais, Belo Horizonte, Brazil
}

Sclareol (SC) is arousing great interest due to its cytostatic and cytotoxic activities in several cancer cell lines. However, its hydrophobicity is a limiting factor for its in vivo administration. One way to solve this problem is through nanoencapsulation. Therefore, solid lipid nanoparticles (SLN-SC) and nanostructured lipid carriers (NLC-SC) loaded with SC were produced and compared regarding their physicochemical properties. NLC-SC showed better SC encapsulation than SLN-SC and was chosen to be compared with free SC in human cancer cell lines (MDA-MB-231 and HCT-116). Free SC had slightly higher cytotoxicity than NLC-SC and produced subdiploid DNA content in both cell lines. On the other hand, NLC-SC led to subdiploid content in MDA-MB-231 cells and G2/M checkpoint arrest in HCT-116 cells. These findings suggest that SC encapsulation in NLC is a way to allow the in vivo administration of $\mathrm{SC}$ and might alter its biological properties.

Keywords: Cancer. Sclareol. Solid lipid nanoparticles. Nanostructured lipid carriers. Small-angle $\mathrm{X}$-ray scattering.

\section{INTRODUCTION}

There is a great effort to discover new compounds with antineoplastic activity derived from plants. This is due to the difficulty in discovering new molecules with therapeutic activity coming solely from chemical synthesis (Atasanov et al., 2015).

"Correspondence: L. A. M. Ferreira. Departamento de Produtos Farmacêuticos. Faculdade de Farmácia. Universidade Federal de Minas Gerais. Avenida Antônio Carlos 6627, 31270-901. Belo Horizonte, Brazil. Phone: +55 31 34096939. Fax: +55 313409 6830. E-mail: lucaufmg@gmail.com
A molecule derived from a vegetal species with interesting pharmacological activity Instead of "is SC", plese change to "is sclareol (SC)" (Figure 1). This is used as a fragrance in cosmetics and as a flavouring agent in the food and pharmaceutical industries, as well as seasoning in Chinese and Mediterranean diets (Noori et al., 2010; Mahaira et al., 2011). First, it was isolated from Salvia sclarea (fam. Labiatae), a native Mediterranean plant with occurrence in southern Europe and Iran, and was later found in conifers (Hatziantoniou et al., 2006; Kuzma et al., 2006).

It has been shown that $\mathrm{SC}$ has antimicrobial (Seo et al., 2012) and antioxidant (Hsieh et al., 2017) activities. 
Moreover, several studies have described its anticancer activity (Dimas et al., 1999, 2001, 2006, 2007; Mahaira et al., 2011). However, the hydrophobicity of SC is a major drawback, which prevents its use in in vivo administrations. An alternative for the administration of hydrophobic compounds such as SC is its delivery in nanostructures (Hatziantoniou et al., 2006).

In previous studies, SC encapsulation in liposomes allowed its intraperitoneal administration in mice at higher doses that could be tolerated if SC was", please change to "that could not be tolerated if SC were in its free form (Dimas et al., 2007; Mahaira et al., 2011). Novel nanocarriers that emerged in the 1990's with interesting properties are solid lipid nanoparticles (SLN) and nanostructured lipid carriers (NLC). They show many advantages over other nanocarriers, including liposomes, such as: avoidance of organic solvents, easy scale-up and diminished production costs. They are constituted by a solid lipid matrix stabilised by surfactants in an aqueous medium. This solid matrix is formed by solid lipids in the case of SLN and by solid and lipid liquids in NLC (Wong et al., 2007; Kalam et al., 2010, 2013; Fang et al., 2013; Beloqui et al., 2016; Bayón-Cordero et al., 2019).

Considering the advantages of SLN and NLC, this work seeks to formulate these systems to load SC as a strategy to allow its in vivo administration by intravenous route. The physicochemical properties of the formulated nanocarriers were evaluated and compared. Moreover, the anticancer activity of NLC-SC in vitro was evaluated in human tumour cell lines and compared to free SC.

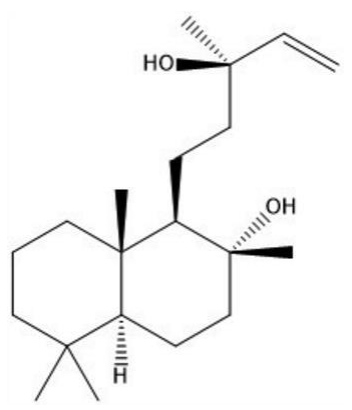

FIGURE 1 - Chemical structure of SC. Abbreviations: SC, sclareol.

\section{MATERIAL AND METHODS}

\section{Material}

Compritol $^{\circledR} 888$ ATO (mixture of mono-, di- and triglycerides of behenic acid) was kindly provided by
Gattefossé, France. Ethoxylated sorbitan monoleate (Tween $^{\mathrm{TM}}$ 80) and peanut oil were kindly provided by Croda, USA. Oleic acid, sodium citrate, dimethyl sulfoxide (DMSO), $\mathrm{SC}$, propidium iodide, and Triton X-100 were purchased from Sigma-Aldrich, Germany. Cell Titer Blue ${ }^{\circledR}$ (CTB) was purchased from Promega, USA. Triethanolamine was purchased from Merck, Germany. Dulbecco's Modified Eagle's Medium (DMEM), Fetal Bovine Serum (FBS), and streptomycin were purchased from Gibco Life Technologies, USA. The other substances used were of analytical grade without further purification.

\section{Preparation of SLN-SC and NLC-SC}

Two nanocarriers were produced for the delivery of SC: an SLN (herein called SLN-SC) and an NLC (herein called NLC-SC). The composition of the oily phase (OP) and aqueous phase (AP) of both nanocarriers is described in Table I. First, the OP was heated to $80^{\circ} \mathrm{C}$ while the AP was also heated separately to the same temperature. With the temperature maintained at $80{ }^{\circ} \mathrm{C}, \mathrm{AP}$ was gently dropped onto the $\mathrm{OP}$ under constant agitation, at $8000 \mathrm{rpm}$, with an Ultra Turrax T-25 homogeniser (IKA Laboratory Equipment, Germany). The formed emulsion was immediately submitted to a high intensity probe sonication for $10 \mathrm{~min}$, as showed in the past works of our group (Castro et al., 2009; Carneiro et al., 2012; Silva et al., 2015, 2016). After this period, the formulations were cooled down to room temperature with manual agitation. The $\mathrm{pH}$ values of SLN-SC and NLC-SC were lowered to the 7.0-7.5 range with a solution of $0.1 \mathrm{M}$ $\mathrm{HCl}$ and the formulations were stored at $4{ }^{\circ} \mathrm{C}$, protected from light in a nitrogen atmosphere.

TABLE I - Composition (\% w/v) of SLN-SC and NLC-SC formulations ${ }^{\text {a }}$

\begin{tabular}{|c|c|c|c|}
\hline & & SLN-SC & NLC -SC \\
\hline \multirow{6}{*}{$\mathrm{OP}$} & Compritol $^{\circledR} 888$ ATO & 1.50 & 1.20 \\
\hline & Peanut oil & $\begin{array}{ll}---- \\
--1\end{array}$ & 0.30 \\
\hline & Tween $^{\mathrm{TM}} 80$ & 0.80 & 0.80 \\
\hline & Triethanolamine & 0.06 & 0.06 \\
\hline & Oleic acid & 0.10 & 0.10 \\
\hline & $\mathrm{SC}$ & 0.20 & 0.20 \\
\hline$\overline{\mathrm{AP}}$ & Water & 100 & 100 \\
\hline \multicolumn{4}{|c|}{$\begin{array}{l}{ }^{a} \mathrm{OP} \text { and } \mathrm{AP} \text { were heated separately at } 80^{\circ} \mathrm{C} \text {, mixed and probe } \\
\text { sonicated to form SLN-SC and NLC-SC. } \\
\text { Abbreviations: SC, sclareol; SLN-SC, sclareol-loaded solid } \\
\text { lipid nanoparticles; NLC-SC, sclareol-loaded nanostructured } \\
\text { lipid carriers. }\end{array}$} \\
\hline
\end{tabular}




\section{Measurement of Particle Size and Zeta Potential}

The mean particle diameter and zeta potential of SLN-SC and NLC-SC were measured by dynamic light scattering (DLS) and DLS coupled with electrophoretic mobility, respectively, using the Zetasizer Nano-ZS90 (Malvern Instruments, United Kingdom) with a fixed angle $\left(90^{\circ}\right)$ laser beam at $25^{\circ} \mathrm{C}$. The SLN-SC and NLCSC dispersions were diluted 100 times in ultrapure water (cellulose ester membrane, $0.45 \mathrm{~mm}$, Millipore, USA) prior to analysis. The data were reported as mean particle size, polydispersity index $(\mathrm{PdI})$, and zeta potential.

\section{Atomic Force Microscopy (AFM)}

AFM observations of SLN-SC and NLC-SC were performed in air at room temperature, on a Dimension 3000 apparatus monitored by a Nanoscope IIIa controller (Digital Instruments, USA). A droplet $(10 \mu \mathrm{L})$ of each formulation (diluted 100 times with ultrapure water) was deposited on a freshly cleaved mica surface, spread all over it, and dried at room temperature. The images were obtained in tapping mode, using commercial silicon probes from Nanosensors ${ }^{\mathrm{TM}}$, with cantilevers having a length of $228 \mu \mathrm{m}$, resonance frequencies of $75-98 \mathrm{kHz}$, spring constants of $29-61 \mathrm{~N} / \mathrm{m}$ and a nominal tip curvature radius of 5-10 nm. The scan rate used was $2 \mathrm{~Hz}$.

\section{Small-angle X-ray Scattering (SAXS)}

SLN-SC and NLC-SC were analysed in the lyophilised form. The lyophilisation of the nanocarriers was performed using a freeze-drier (ModulyoD Freeze Dryer, ThermoFisher, USA) connected to a VLP120 vacuum pump (ThermoFisher, USA). SLN-SC and NLC$\mathrm{SC}$ were rapidly frozen with the aid of liquid nitrogen and then the frozen SLN-SC and NLC-SC were lyophilised at a temperature of $-45^{\circ} \mathrm{C}$ for $24 \mathrm{~h}$.

SAXS measurements were carried out at the SAXS1 beamline of the Brazilian Synchrotron Light Laboratory (LNLS, Campinas, Brazil), using a fixed X-ray wavelength $\lambda=0.1488 \mathrm{~nm}$. The scattered $\mathrm{x}$-ray photons were detected using a Pilatus $300 \mathrm{~K}$ detector, covering a momentum transfer reciprocal space range of $0.5<\mathrm{Q}<4.5 \mathrm{~nm}^{-1}$, where $\mathrm{Q}=(4 \pi / \lambda) \sin \theta$ and $\theta$ is the scattering angle.

The samples were placed inside metal rings, which were sealed by a polyimide film $\left(\right.$ Kapton $\left.^{\circledR}\right)$. The lattice spacing was calculated from our measurements using the formula $d=2 \pi / Q$, which is valid for the first-order peaks of all structure types analysed in this work. Domain sizes (L) were extracted using the reciprocal space width $(\Delta \mathrm{Q})$ of the first order peak of each measurement, as $\mathrm{L}=$ $2 \pi / x$ tracted using the reciprocal space wQ (an intrinsic instrument broadening of $0.01 \mathrm{~nm}^{-1}$ was considered for all calculations).

\section{Fourier-transform Infrared Spectroscopy (FTIR)}

The FTIR was employed to characterise the typical functional groups present in the chemical composition of SC, Compritol ${ }^{\circledR} 888$ ATO, SLN-SC and NLC-SC (the nanocarriers were analysed in the lyophilised form). FTIR spectra were obtained on a Spectrum One ATR system (Perkin-Elmer, USA), in the range of $4000-650 \mathrm{~cm}^{-1}$ at room temperature.

\section{Differential Scanning Calorimetry (DSC)}

Bulk materials (Compritol ${ }^{\circledR} 888$ ATO and SC) and lyophilised nanocarriers (SLN-SC and NLC-SC) were placed in aluminium pans. DSC analyses were performed in a DSC-60 differential scanning calorimeter (Shimadzu, Japan). The heating rate was $10{ }^{\circ} \mathrm{C} / \mathrm{min}$ with a nitrogen flow of $50 \mathrm{~mL} / \mathrm{min}$. The range of temperature was 40 $150^{\circ} \mathrm{C}$.

\section{Polarised Light Microscopy (PLM)}

The encapsulation of SC in the lipid core of the nanocarriers was evaluated by PLM. The presence of SC crystals in SLN-SC and NLC-SC dispersions was evaluated by an optical microscope (Zeiss Axio Imager.M2, Carl Zeiss, Germany) coupled with a light polariser and equipped with an AxioCam digital camera (Model ERc 5S, Carl Zeiss, Germany). The samples were prepared in microscope slides (undiluted) and the detection of SC crystals indicated a non-encapsulation of the diterpene in the nanostructures.

\section{Cell Culture}

ATCC ${ }^{\circledR}$ HTB-26 (MDA-MB-231), a human breast adenocarcinoma cell line was purchased from ATCC $^{\circledR}$ (American Type Culture Collection), USA. ATCC ${ }^{\circledR}$ CCL-247 (HCT-116), a human carcinoma cell line, was kindly donated by Professor Adriana Abalen (Genetic Department, Biological Science Department, Federal University of Minas Gerais, Brazil). Cells were 
grown and maintained in DMEM medium supplemented with FBS $(10 \% \mathrm{v} / \mathrm{v})$ and penicillin $(100 \mathrm{IU} / \mathrm{mL})$ in a $5 \%$ $\mathrm{CO}_{2}$ atmosphere at $37^{\circ} \mathrm{C}$.

\section{Cytotoxicity Assays}

Cells were seeded in 96-well tissue culture plates at $5 \times 10^{3}$ cells/well about $24 \mathrm{~h}$ before the treatment. Free SC was freshly prepared by dissolving the diterpene in DMSO. The cytotoxicity of NLC-SC and free SC was evaluated in a range of SC concentrations between 1.9 and $120 \mu \mathrm{M}$. Blank-NLC (without SC) were diluted as NLC-SC in the whole range of concentrations used. In order to calculate the dose of SC in the NLC-SC, we considered that $100 \%$ efficiency encapsulation of sclareol was obtained in accordance with the past works that we have published encapsulating hydrophobic drugs (Castro, 2009; Carneiro et al., 2012; Silva et al., 2015, 2016). The cells were incubated with the treatments for $24 \mathrm{~h}$ and, after this period, the whole medium was replaced by a mixture of supplemented DMEM with $\mathrm{CTB}^{\circledR}$ (a solution of the cell viability reagent resazurin), to assess cytotoxicity in this period. The incubation was performed for $2 \mathrm{~h}$ and the fluorescence intensity was measured using Cytation ${ }^{\circledR} 5$ equipment (BioTek, USA) at 530/590 nm excitation/emission wavelengths. Three independent experiments were performed at least in triplicate and DMSO (0.5\%) control was performed. Determination of inhibitory concentration of $50 \%$ of cell viability $\left(\mathrm{IC}_{50}\right)$ values was determined using the software GraphPad Prism ${ }^{\circledR}$ 5.0.

\section{Cell Cycle Analyses}

A flow cytometric assay was employed to measure the DNA content in the cells after the treatments with NLC-SC and free SC, as described by Nicoletti et al. (1991). Briefly, aliquots containing $2 \times 10^{5}$ cells/well were seeded into 24 -well plates and incubated for $24 \mathrm{~h}$. After incubation, cells were treated with free SC, NLC-SC, and Blank-NLC for $24 \mathrm{~h}$ (SC concentrations: 60 and $120 \mu \mathrm{M}$ ). DMSO in the same concentration used to solubilise free SC $(0.25$ and $0.5 \%)$ was used as negative control.

After treatment time, cells were centrifuged, suspended in a hypotonic fluorochrome solution-HFS $(50 \mu \mathrm{g} / \mathrm{mL}$ propidium iodide in $0.1 \%$ sodium citrate plus $0.1 \%$ Triton X-100) and incubated at $4{ }^{\circ} \mathrm{C}$ for $4 \mathrm{~h}$. The propidium iodide fluorescence of 10,000 individual nuclei was measured using a FACScan flow cytometer (Becton Dickinson, USA). Three experiments were performed in triplicate. Data were analysed using FlowJo software 7.5.5 (TreeStarInc., USA).

\section{Data Analysis}

Statistical analyses were carried out using KruskalWallis test followed by Dunn $t$ test for the average size, PdI, and zeta potential. Cytotoxicity assays and cell cycle analyses were performed using two-way analysis of variance followed by Bonferroni's t test. For all analyses, the difference was considered statistically significant when $P$ value was less than 0.05 .

\section{RESULTS}

\section{SLN-SC and NLC-SC characterisation}

The data for average diameter, PdI, and zeta potential are shown in Table II. No differences were seen between SLN-SC and NLC-SC and between blank formulations and the SC-loaded ones, regarding these parameters.

It was also evaluated whether there was some difference regarding the shape and size of the nanocarriers by AFM analyses. The images are shown in Figure 2. For both SLN-SC and NLC-SC, the presence of particles of spherical or quasi-spherical shape was observed. This method, which has poor overall statistics, provided lateral sizes smaller than those seen in DLS analyses (Table II). 
A
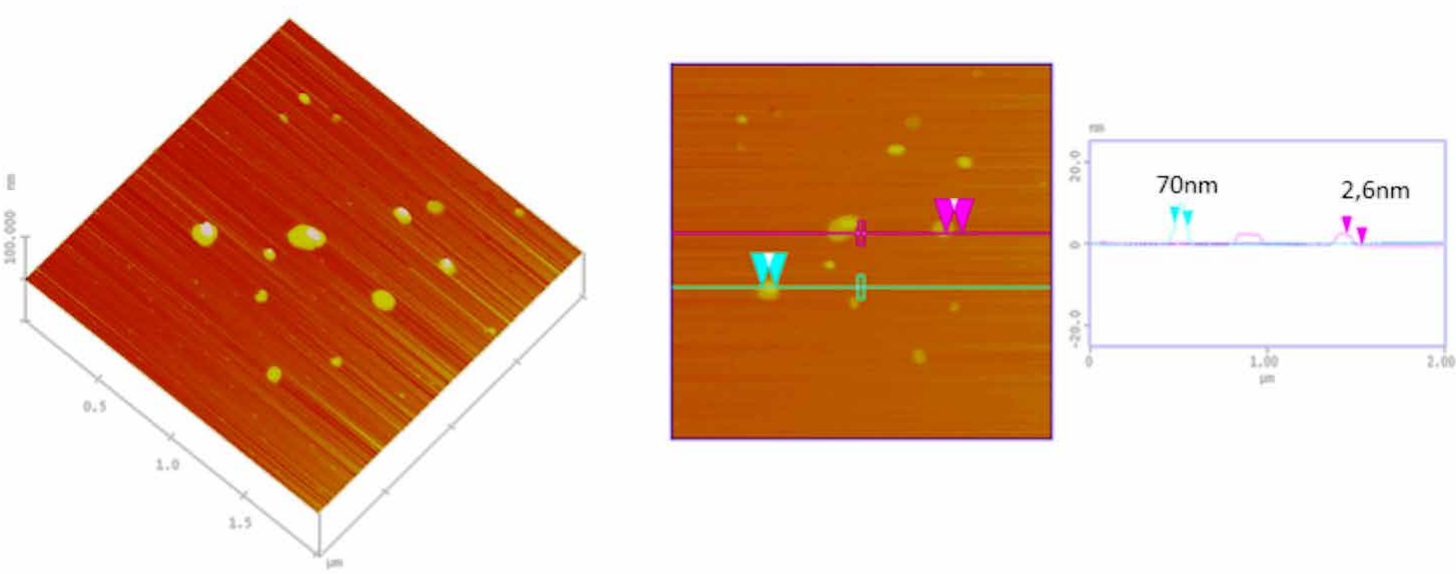

B
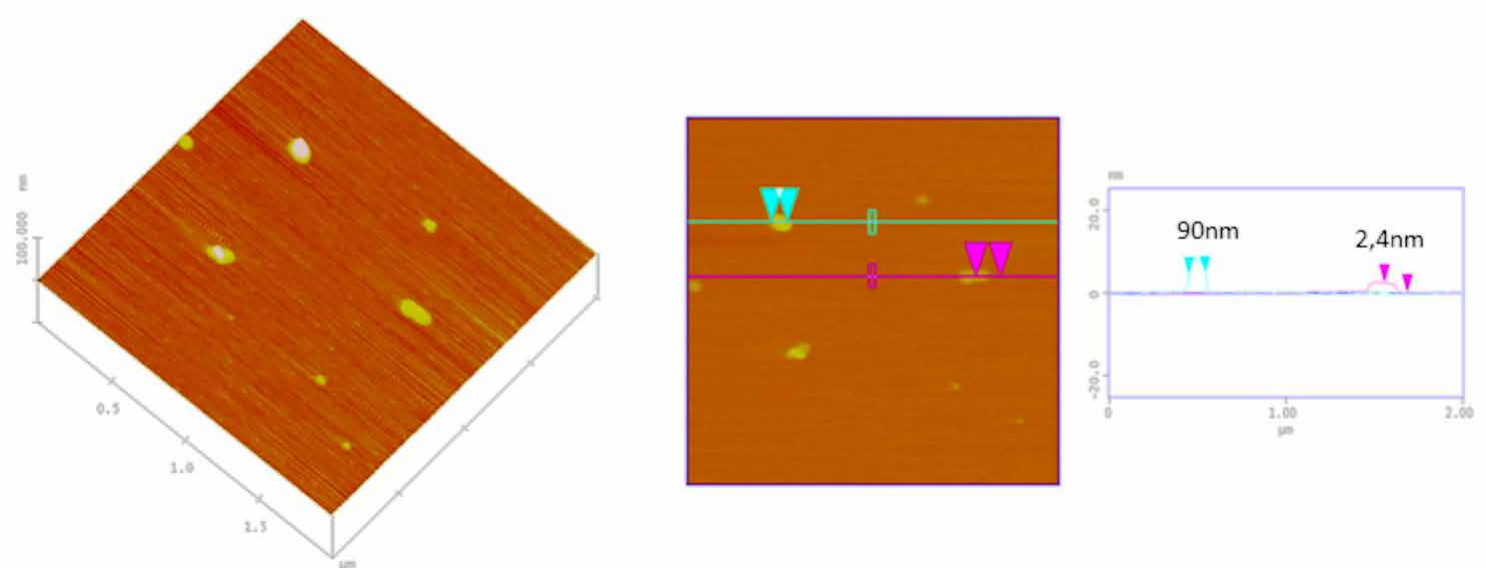

FIGURE 2 - Tapping mode-AFM images of (A) SLN-SC and (B) NLC-SC. Shapes similar to spherical can be seen for both nanocarriers. Measurement of the size and height of one example of each nanocarrier is also shown. Abbreviations: AFM, atomic force microscopy; SLN-SC, sclareol-loaded solid lipid nanoparticles; NLC-SC, sclareol-loaded nanostructured lipid carriers.

TABLE I - Average size, PdI and zeta potential data obtained by DLS for SLN and NLC loaded with SC and blank formulations ${ }^{\text {a }}$

\begin{tabular}{lcccc}
\hline & Blank-SLN & SLN-SC & Blank-NLC & NLC-SC \\
\hline Particle size (nm) & $126 \pm 6$ & $127 \pm 16$ & $124 \pm 8$ & $115 \pm 5$ \\
\hline PdI & $0.26 \pm 0.01$ & $0.30 \pm 0.05$ & $0.25 \pm 0.03$ & $0.23 \pm 0.02$ \\
\hline Zeta potential (mV) & $-26 \pm 2$ & $-27 \pm 2$ & $-27 \pm 4$ & $-22 \pm 7$ \\
\hline
\end{tabular}

${ }^{a}$ Results shown as mean \pm standard deviation $(\mathrm{n}=3$ ).Abbreviations: PdI, polydispersity index; DLS, Dynamic Light Scattering; Blank-SLN, blank (without SC)-solid lipid nanoparticles; SLN-SC, sclareol-loaded solid lipid nanoparticles; Blank-NLC, blank (without SC)-nanotructured lipid carriers; NLC-SC, sclareol-loaded nanostructured lipid carriers. 
SLN-SC and NLC-SC samples were lyophilised and visual inspection proved the success of the process, with a homogenous powder formed. Although NLC-SC presents oil in its composition, lyophilisation of different types of NLC has been performed successfully (Liu et al., 2008; Li et al., 2010; Marquele-Oliveira et al., 2010; Patil-Gadhe et al., 2014). Jenning et al. (2000a, 2000b) showed that only in concentrations of oil above $28 \%$ (higher than what is present in NLC-SC), oily clusters were found within the NLC structure.

The analysis of SAXS measurements provides more information on the structure of SLN-SC and NLC-SC and their differences. Figure 3(A) shows the diffractograms of Compritol ${ }^{\circledR} 888$ ATO, SLN-SC, and
NLC-SC. One observes that the three peaks seen for Compritol $^{\circledR} 888$ ATO, located at $\mathrm{Q}=1 \mathrm{~nm}^{-1} ; 2 \mathrm{~nm}^{-1}$, and $3 \mathrm{~nm}^{-1}$, are also found for NLC-SC $\left(\mathrm{Q}=1.07 \mathrm{~nm}^{-1}\right.$, $2.16 \mathrm{~nm}^{-1}$, and $\left.3.23 \mathrm{~nm}^{-1}\right)$ and SLN-SC $\left(\mathrm{Q}=1.07 \mathrm{~nm}^{-1}\right.$, $2.13 \mathrm{~nm}^{-1}$, and $3.20 \mathrm{~nm}^{-1}$ ). The ratio of approximately $1: 2: 3$ for the peak positions denotes that the same lamellar pattern of organization was found in all cases. Moreover, although the peak positions were similar, the peaks observed for nanocarriers were slightly displaced towards higher Q values when compared to the Compritol ${ }^{\circledR} 888$ ATO ones. This is directly related to a larger lamellar lattice spacing for the bulk material $(6.26 \mathrm{~nm})$, if compared to SLN-SC (5.91 nm) and NLC$\mathrm{SC}(5.88 \mathrm{~nm})$ (Figure 3(B)).
B
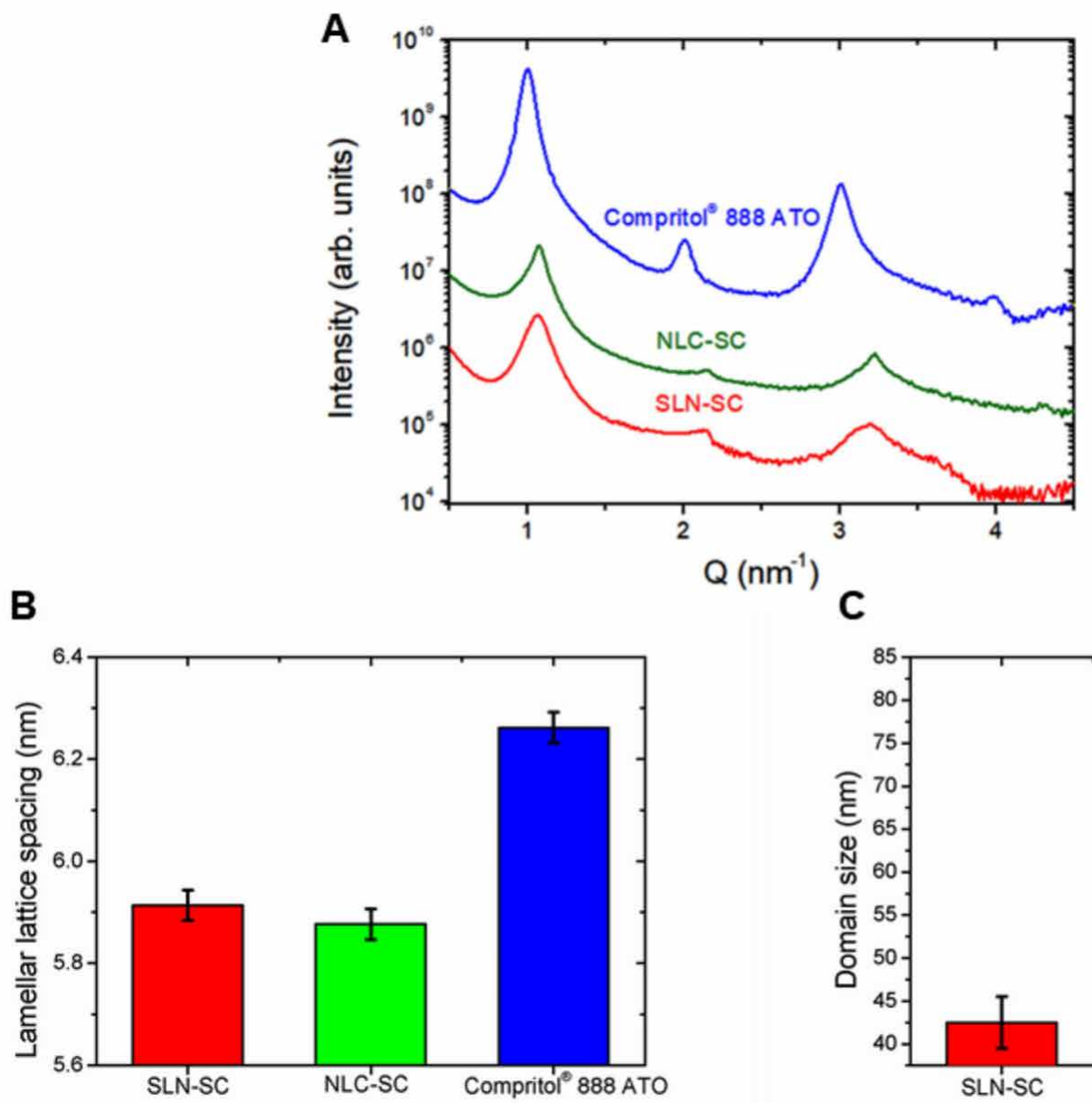

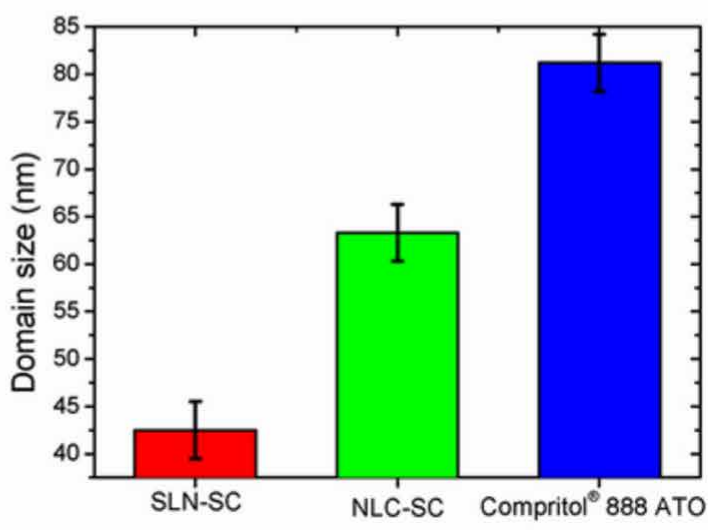

FIGURE 3 - SAXS measurements: (A) SAXS patterns for Compritol ${ }^{\circledR} 888$ ATO and lyophilised nanocarriers (SLN-SC and NLC-SC), (B) lamellar lattice spacing and (C) domain size of Compritol ${ }^{\circledR} 888$ ATO and lyophilised nanocarriers (SLN-SC and NLC-SC). Abbreviations: SAXS, small-angle x-ray scattering; SLN-SC, sclareol-loaded solid lipid nanoparticles; NLC-SC, sclareol-loaded nanostructured lipid carriers. 
More pronounced differences were detected between the nanocarriers when the domain size was evaluated. This parameter was correlated with the inverse of the reciprocal space width of the peaks. Compritol $^{\circledR} 888$ ATO showed the highest domain size among the three groups $(81.2 \mathrm{~nm})$. The calculated average domain size of SLN-SC was $42.5 \mathrm{~nm}$, while for NLC-SC a domain size of $63.3 \mathrm{~nm}$ was retrieved (Figure 3(C)). Although comparable to AFM size analyses (Figure 2), the observed SAXS sizes were smaller than those measured by DLS (Table II). This can be ascribed to incoherent agglomeration, in which the lattice registry of neighbour particles is broken (restricting the SAXS domain size), not affecting the DLS results.
Figure 4 shows the FTIR analysis of SC, Compritol $^{\circledR}$ 888 ATO and the nanocarriers (SLN-SC and NLC-SC). The absorption bands in the $\mathrm{SC}$ spectrum regarding $\mathrm{C}=\mathrm{C}$ in alkene such as $1644 \mathrm{~cm}^{-1}$ (stretching) and $967 \mathrm{~cm}^{-1}$ (bending) were not seen in the SLN-SC and NLC-SC samples. Compritol ${ }^{\circledR} 888$ ATO, SLN-SC, and NLC-SC showed practically the same FTIR spectra, including the characteristic absorption band at $1736 \mathrm{~cm}^{-1}$ related to the stretching of the $\mathrm{C}=\mathrm{O}$ ester bond. Nevertheless, in the SLN-SC and NLC-SC spectra, there was a broadening and a shifting of the $\mathrm{C}-\mathrm{O}$ ester bond related to Compritol ${ }^{\mathbb{B}}$ 888 ATO. While a sharp absorption band at $1175 \mathrm{~cm}^{-1}$ was observed in the bulk material broader bands were observed at $1107 \mathrm{~cm}^{-1}$ for SLN-SC and at $1109 \mathrm{~cm}^{-1}$ for NLC-SC.

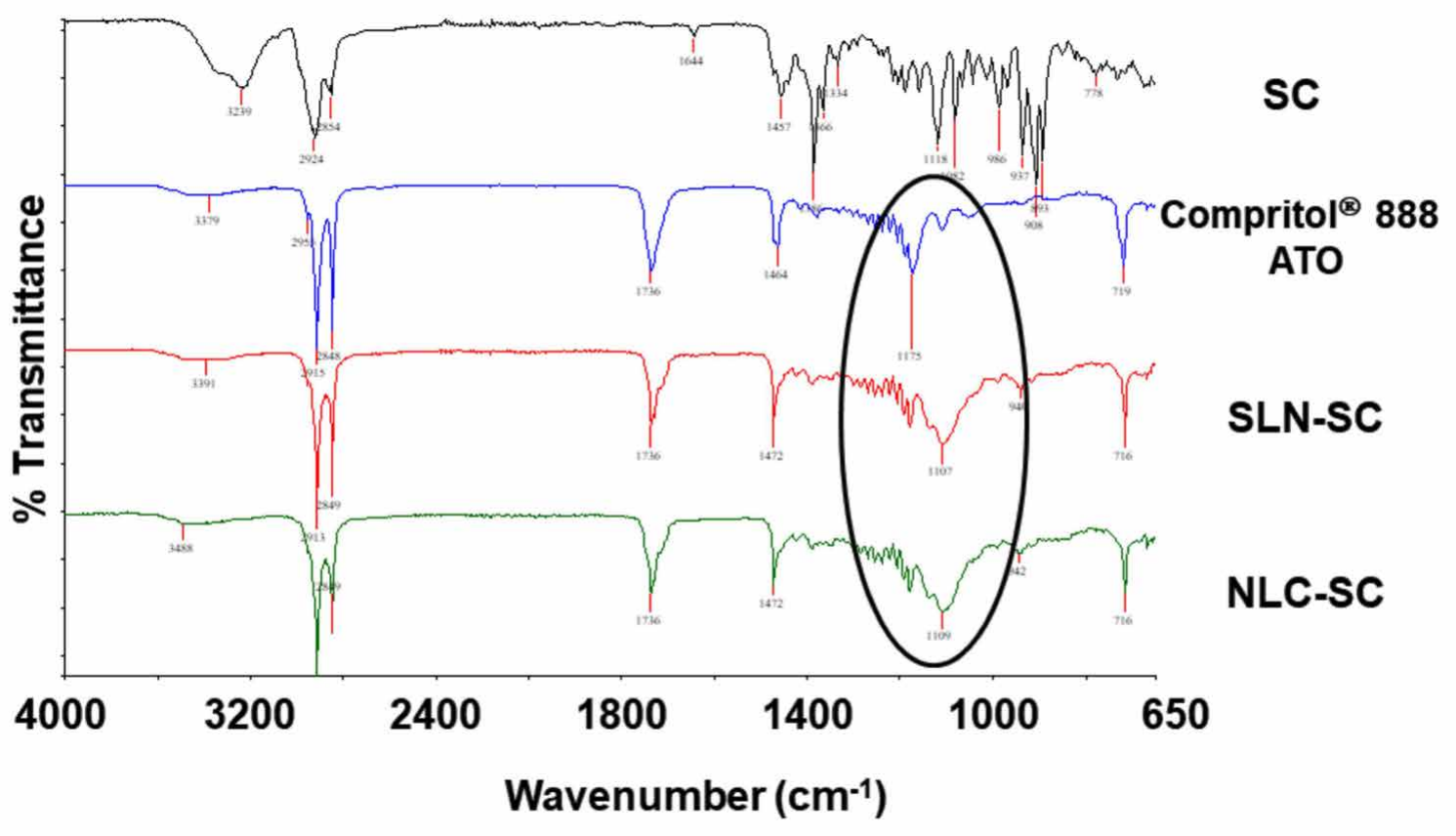

FIGURE 4 - FTIR spectra of SC, Compritol ${ }^{\circledR} 888$ ATO, SLN-SC, and NLC-SC. The area circled highlights the difference in the absorption bands between Compritol ${ }^{\circledR} 888$ ATO and the nanocarriers (SLN-SC and NLC-SC). Abbreviations: FTIR, Fouriertransform infrared spectroscopy; SLN-SC, sclareol-loaded solid lipid nanoparticles; NLC-SC, sclareol-loaded nanostructured lipid carriers.

The lipid matrix structuration was also evaluated by DSC (Figure 5). Table III shows the values found for the melting point peaks of the solid bulk materials (Compritol ${ }^{\circledR}$ 888 ATO and SC) and the nanocarriers (SLN-SC and NLC-SC). The DSC analyses for the SLN-SC and NLCSC showed melting point peaks broader and less defined than those seen for Compritol ${ }^{\circledR} 888$ ATO, the solid lipid that constitutes the matrix of both nanocarriers. The melting point peak temperature of Compritol ${ }^{\circledR} 888 \mathrm{ATO}$ $\left(72.45^{\circ} \mathrm{C}\right)$ was also lower than those observed for the nanocarriers (67.93 and $68.94{ }^{\circ} \mathrm{C}$ for SLN-SC and NLC$\mathrm{SC}$, respectively). Moreover, when comparing SLN-SC curve to the NLC-SC one, the $\Delta \mathrm{T}$ (difference between the onset and endset melting point temperatures) for NLC$\mathrm{SC}$ was higher than that for SLN-SC $\left(10.84\right.$ vs $7.75^{\circ} \mathrm{C}$, respectively). 


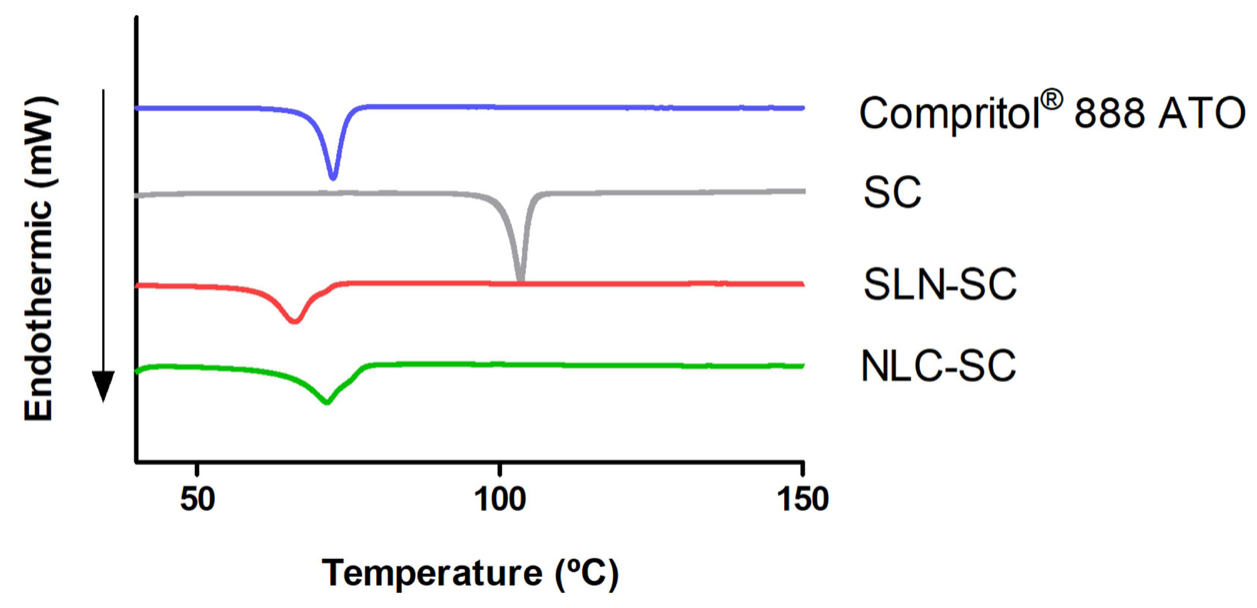

FIGURE 5- DSC curves for the bulk materials and lyophilised nanocarriers. Samples were heated from 40 to $150{ }^{\circ} \mathrm{C}$. Very defined peaks can be observed for Compritol ${ }^{\circledR} 888$ ATO and SC. On the contrary, broad peaks are found for SLN-SC and NLC-SC, with the one regarding NLC-SC broader than the one seen for SLN-SC. Abbreviations: DSC, differential scanning calorimetry; SC, sclareol; SLN-SC, sclareol-loaded solid lipid nanoparticles; NLC-SC, sclareol-loaded nanostructured lipid carriers.

TABLE III - Melting temperatures events of bulk materials and lyophilised nanocarriers obtained by DSC (range of temperature tested: $\left.40-150{ }^{\circ} \mathrm{C}\right)^{\text {a }}$

\begin{tabular}{lllll}
\hline & PT & OT & ET & $\Delta$ T \\
\hline Compritol $^{\circledR} 888$ ATO & 72.45 & 69.58 & 74.82 & 5.24 \\
\hline SC & 100.94 & 99.17 & 102.81 & 3.64 \\
\hline SLN-SC & 67.93 & 63.96 & 71.71 & 7.75 \\
\hline NLC-SC & 68.94 & 62.56 & 73.40 & 10.84 \\
\hline
\end{tabular}

a Values expressed in ${ }^{\circ} \mathrm{C}$.

Abbreviations: PT, melting peak temperature; OT, onset melting temperature; ET, endset melting temperature; $\Delta \mathrm{T}$, difference between onset and endstet melting point temperatures; SC, sclareol; SLN-SC, sclareol-loaded solid lipid nanoparticles; NLCSC, sclareol-loaded nanostructured lipid carriers.

Finally, the encapsulation of SC in SLN-SC and NLC-SC was compared qualitatively by PLM. The presence of SC crystals was clearly visualised in the SLNSC aliquots when they were subjected to PLM, whereas these crystals were not visualised for NLC-SC (Figure 6). This result shows that retention of SC was improved for
NLC-SC in comparison to SLN-SC. Therefore, NLC-SC was selected to be evaluated in the biologic (cytotoxicity and cell cycle) assays. 
A

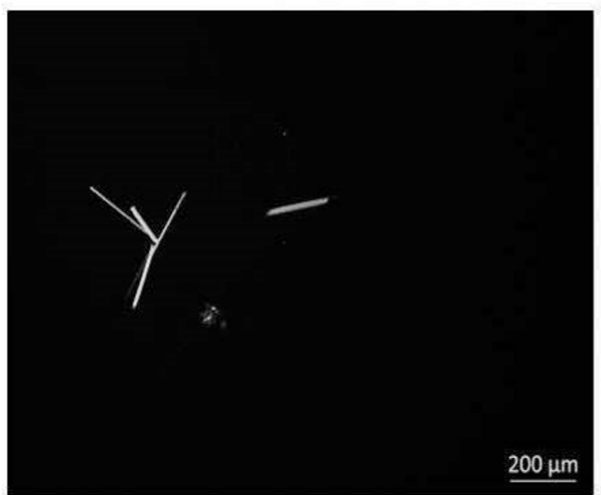

B

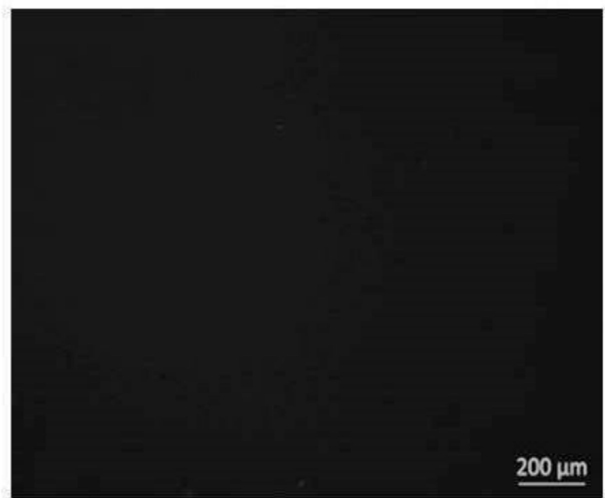

FIGURE 6 - PLM images for (A) SLN-SC and (B) NLC-SC. It can be clearly visualised SC crystals for SLN-SC aliquots while they are not observed for NLC-SC aliquots, confirming SC effective encapsulation in the latter. Abbreviations: PLM, polarised light microscopy; SLN-SC, sclareol-loaded solid lipid nanoparticles; NLC-SC, sclareol-loaded nanostructured lipid carriers.

\section{Cytotoxicity Assays}

The cytotoxicity of NLC-SC against MDA-MB-231 and HCT-116 cell lines was evaluated (Figure 7). Free SC and Blank-NLC were also tested. First, it can be seen that in both cell lines, Blank-NLC did not show significant cytotoxicity in the evaluated concentrations. This shows that the materials that constitute the NLC are safe and that they do not engender cytotoxicity by themselves, even though no sterilisation was previously performed.

For the MDA-MB-231 cell line, the cytotoxicity induced by the NLC-SC was similar to that observed for free $\mathrm{SC}$ until the $30 \mu \mathrm{M}$ SC concentration. However, when SC concentration was 60 or $120 \mu \mathrm{M}$, the activity of the free drug was significantly higher than that observed for NLC-SC. For the HCT-116 cell line, a similar phenomenon was observed with non-significant differences between NLC and SC until the SC concentration reached $15 \mu \mathrm{M}$. When higher concentrations were used (30 and $60 \mu \mathrm{M})$, free SC induced a significantly higher cytotoxicity than that observed for NLC-SC (Figure 7). The $\mathrm{IC}_{50}$ values found for free SC and NLC-SC in both cell lines are shown in Table IV.
MDA MB-231

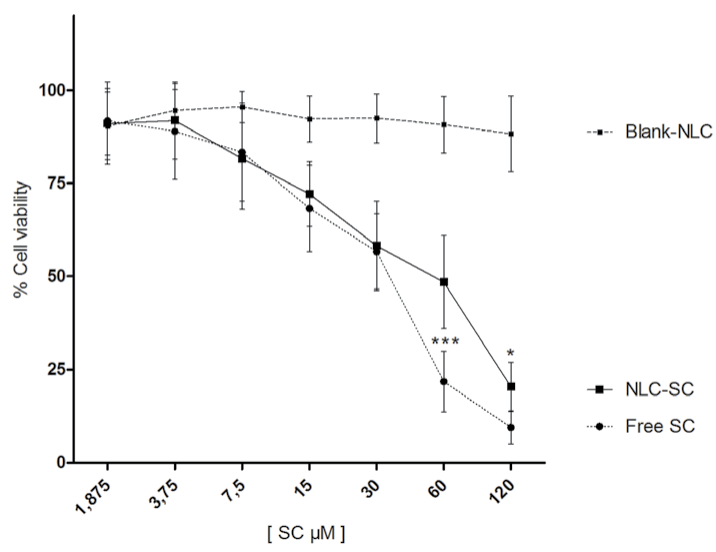

HCT-116

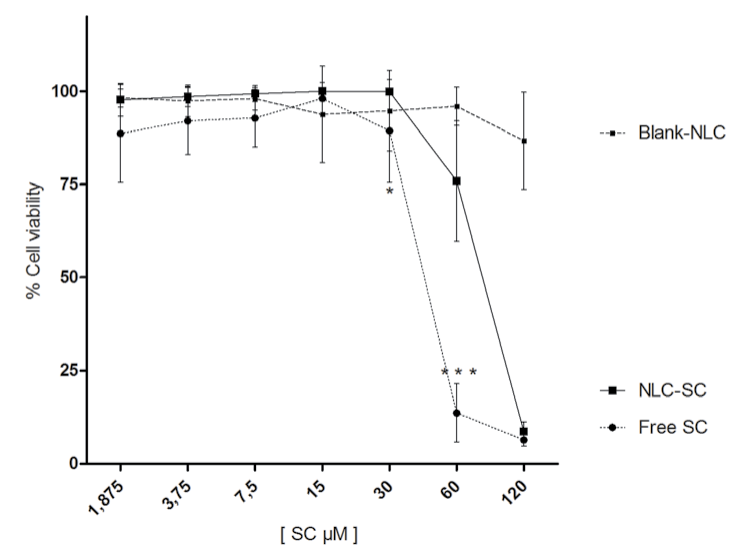

FIGURE 7 - Cell viability curves for MDA-MB-231 and HCT-116 cell lines determined by CTB ${ }^{\circledR}$ reagent assay. Samples were incubated for $24 \mathrm{~h}$ with cells (5x103 cells/well) and cytotoxicity was shown as the percentage of viability comparing with control (no-treated cells). ${ }^{a}$ Results shown as media \pm standard deviation $(n=3) . *=$ significantly different from NLC-SC group $(\mathrm{P}<0.05) ; * * *=$ significantly different from NLC-SC group $(\mathrm{P}<0.001)$. Abbreviations: Blank-NLC, unloaded nanostructured lipid carrier; NLC-SC, sclareol-loaded nanostructured lipid carrier; SC, sclareol. 
TABLE IV - $\mathrm{IC}_{50}$ values $(\mu \mathrm{M})$ for free SC and NLC-SC in MDA-MB-231 and HCT-116 cell lines after $24 \mathrm{~h}$ of incubation a

\begin{tabular}{lcc}
\hline & MDA-MB-231 & HCT-116 \\
\hline Free SC & $28 \pm 2$ & $45 \pm 6$ \\
\hline NLC-SC & $42 \pm 3$ & $75 \pm 8$ \\
\hline
\end{tabular}

${ }^{\text {a }}$ Results showed as mean \pm standard deviation $(\mathrm{n}=3)$.

Abbreviations: SC, sclareol; NLC-SC, sclareol-loaded nanostructured lipid carriers.

\section{Cell Cycle Analyses}

To investigate if the differences seen in the cell viability assays between NLC-SC and free SC interfere in other parameters, cell cycle analyses were performed.
Two concentrations of SC were used: 60 and $120 \mu \mathrm{M}$. These concentrations were chosen as they were the highest ones used in cell viability studies and therefore were more likely to alter the cell cycle behaviour.

Blank-NLC showed similar behaviour to the negative control (DMSO) in both concentrations for both cell lines. Free SC showed an increase in the subdiploid (sub $\mathrm{G}_{0} / \mathrm{G}_{1}$ ) content compared to negative controls for $120 \mu \mathrm{M} \mathrm{SC}$ concentration in MDA-MB-231 and HCT-116 cells lines (Figure 8(A) and 8(B)).

For the MDA-MB-231 cell line, NLC-SC showed an increase in subdiploid content in the concentration of 60 and $120 \mu \mathrm{M}$ of SC in comparison with negative controls. In addition, for $\mathrm{SC}$ concentration of $120 \mu \mathrm{M}$, this increase was significantly higher than that observed for free SC (Figure 8(A)). In contrast, in HCT-116 cell line (SC at 120 $\mu \mathrm{M})$, NLC-SC did not generate any increase in subdiploid DNA content. Instead, an increase was observed in the amount of DNA in the $\mathrm{G}_{2} / \mathrm{M}$ phases compared to the negative control group (Figure 8(B)).
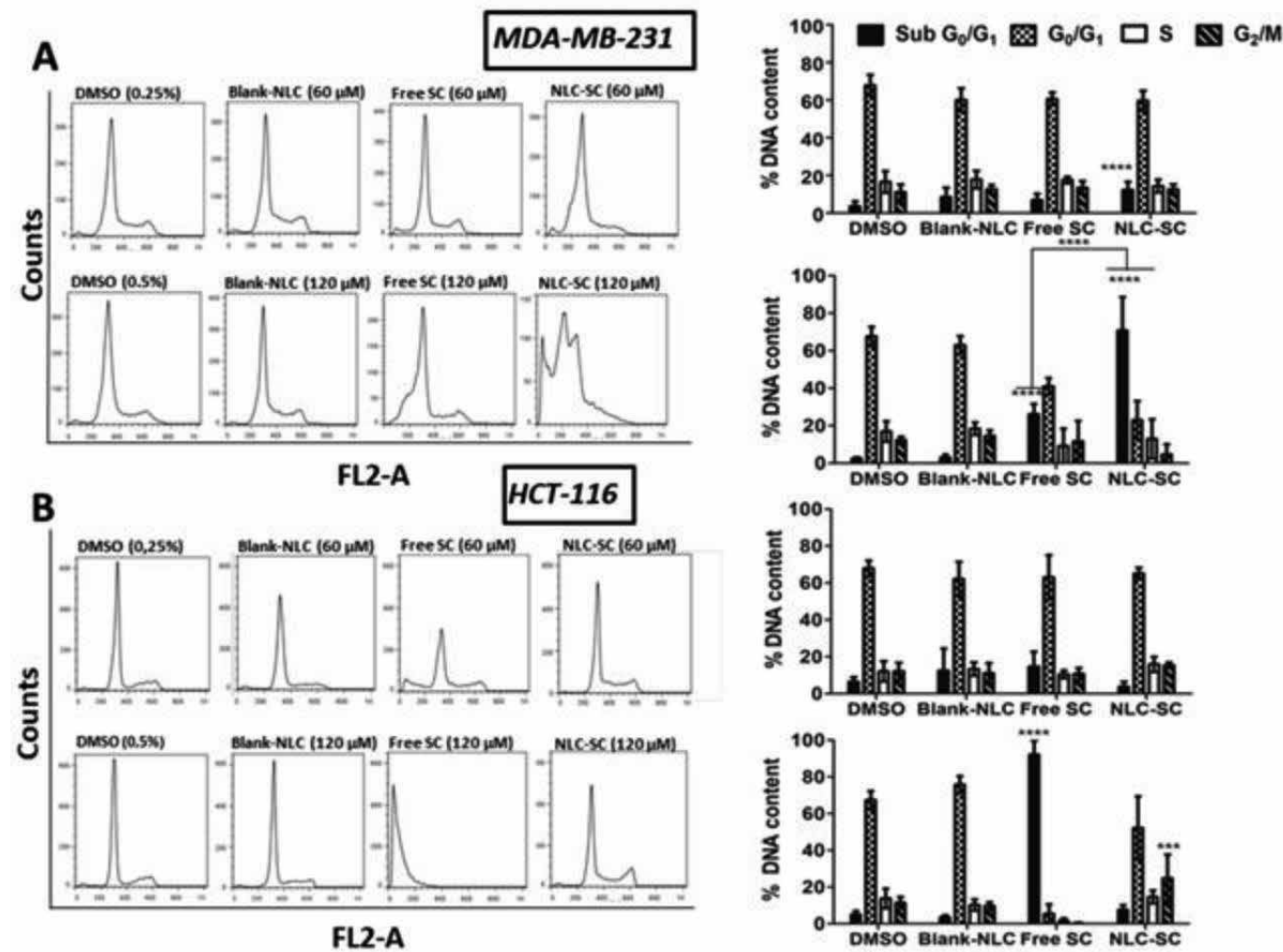

FIGURE 8 - Representative histograms of 3 experiments in triplicate and quantification of DNA content in each phase (sub G0/ $\mathrm{G}_{1}, \mathrm{G}_{0} / \mathrm{G}_{1}, \mathrm{~S}$, and $\mathrm{G}_{2} / \mathrm{M}$ ) of the cell cycle for MDA-MB-231 (A) and HCT-116 (B) treated with free SC and NLC-SC. MDAMB-231 and HCT-116 cells ( $5 \times 10^{3}$ cells/well) were incubated for $24 \mathrm{~h}$ with the treatments. ${ }^{\text {a }}$ Results shown as mean \pm standard deviation $(\mathrm{n}=3)$. Differences to negative control $(\mathrm{DMSO})$ and between free SC and NLC-SC are shown. ${ }_{* * *}=$ significantly different $(\mathrm{P}<0.001) ;_{* * * *}=$ significantly different $(\mathrm{P}<0.0001)$. Abbreviations: DMSO, dimethylsulfoxide; Blank-NLC, unloaded nanostructured lipid carrier; NLC-SC, sclareol-loaded nanostructured lipid carrier; SC, sclareol. 


\section{DISCUSSION}

This study aimed to develop, characterise and evaluate the in vitro anticancer activity of nanocarriers loaded with SC, a labdane diterpene which presents cytotoxic activity against several cancer cell lines. SC has high hydrophobicity, impairing its use in vivo. Therefore, a nanocarrier that efficiently encapsulates $\mathrm{SC}$ can be an interesting alternative to promote its intravenous use, one of the most used routes for antineoplastic administration (Mazzaferro et al., 2013).

Two types of distinct lipid nanoparticles were prepared for the encapsulation of SC: SLN-SC and NLCSC. The difference between the two types of formulation lies in the composition of the lipid matrix. While for the SLN-SC, the lipid matrix is formed only by a solid lipid (Compritol ${ }^{\circledR} 888$ ATO), for NLC-SC, in addition to Compritol $^{\circledR}$, the lipid matrix has a liquid lipid in its composition: peanut oil (a long-chain triglyceride). We intended to evaluate the differences between SLN-SC and NLC-SC to choose one of them to perform biological assays.

Both SLN-SC and NLC-SC had the desired size for intravenous administration aiming a passive target to the tumours (Table II). It is well described in the literature that the vascular endothelium in solid tumours has plenty of fenestrations and an inefficient lymphatic uptake, which would allow the accumulation of nanoparticles (up to 200 $\mathrm{nm}$ ) in the tumour sites (Taurin et al., 2012). Moreover, both nanocarriers had low polydispersity index (up to 0.30) and a negative zeta potential, which will promote electrostatic stability between the nanoparticles (Benita, Levy, 1993).

The shape of SLN-SC and NLC-SC particles was evaluated by AFM (Figure 2). AFM imaging is among the most used microscopic techniques to investigate the morphology of nanocarriers due to the ease of analysis (Wang et al., 2012). Both SLN-SC and NLC-SC exhibited formats that resemble a spherical shape, which has been reported previously for SLN and NLC in AFM analyses (Akanda et al., 2015; Nahak et al., 2016). The sizes of SLN-SC and NLC-SC were similar (in Figure 2 , we highlight the size of typical SLN-SC and NLCSC particles and smaller than those observed in DLS analyses (Table II). One explanation could be that the average size given by DLS does not represent the size of the majority of the particles. In the size distribution by number (Supplementary data, Figure S1) of NLC$\mathrm{SC}$ and SLN-SC, it is possible to see that the majority of the particles have sizes lower than $100 \mathrm{~nm}$ for both nanocarriers, explaining the smaller sizes retrieved in the AFM images. The absence of a unimodal distribution in number distribution (Supplementary data, Figure S1) is not a limiting factor, as the requisites for intravenous injection according to the United States Pharmacopoeia are a mean diameter less than $500 \mathrm{~nm}$ and a maximum $0.05 \%$ presence of particles with a diameter higher than $5 \mu \mathrm{m}$ (USP, 2009), requisites that are both fulfilled by the NLC-SC. Moreover, it is possible to see that the height of the particles is very small. This is due to interactions between the samples and the cantilever tip in AFMtapping mode analyses, which flattens the nanocarriers (Ebenstein et al., 2002).

SAXS analyses were also used to evaluate the size and the structure of the nanocarriers. In Figure 3(A), it is possible to see the periodicity ratio $(1,2$, and 3$)$ of the peaks for Compritol ${ }^{\circledR} 888$ ATO, SLN-SC, and NLC$\mathrm{SC}$ curves, implying a lamellar pattern of arrangement that was previously reported for similar types of lipid nanocarriers (Lukowski et al., 2000). Moreover, it is clearly seen that the peaks of Compritol ${ }^{\circledR} 888$ ATO are much more intense than the ones from the nanostructures. This loss of intensity refers to a lower crystallinity (higher disorder) of the nanocarriers, if compared to the bulk material which has already been reported in other works (Castro et al., 2009).

Regarding the lamellar lattice spacing, similar values were observed for SLN-SC and NLC-SC. Jenning et al. (2000a) compared SLN composed only of Compritol ${ }^{\mathbb{R}}$ 888 ATO and NLC composed of Compritol ${ }^{\circledR} 888$ ATO and different proportions of Miglyol ${ }^{\circledR} 812$, a liquid lipid. They did not detect any correlation between the presence of oil and an increase or reduction in the lamellar spacing.

Finally, it was noticed that the domain sizes were different for the groups analysed. As expected, Compritol ${ }^{\circledR}$ 888 ATO had larger domain sizes than the nanostructures. This is probably due to the fact that, when the lipid is in its bulk form, its molecules are arranged in well behaved crystals that are larger than the chemically complex nanoparticles. As in the AFM analyses (Figure 2), the sizes detected for SLN-SC and NLC-SC were smaller than the ones observed by DLS (Table II). However, looking at the size distribution by number obtained from DLS for SLN-SC and NLC-SC (supplementary data, Figure S1), one observes that the size of the most intense peaks for SLN-SC $(41.1 \mathrm{~nm})$ and NLC-SC $(54.6 \mathrm{~nm})$ are close to the domain sizes detected by SAXS (42.5 nm for SLN-SC and $63.3 \mathrm{~nm}$ for NLC-SC). 
In the FTIR spectra (Figure 4), it is easily noted that the absorption bands for SLN-SC and NLC-SC are the same for Compritol ${ }^{\circledR} 888$ ATO. Moreover, none of the characteristic SC bands are observed for the SLN-SC and NLC-SC samples. Nevertheless, this was expected, as in proportion, the majority of the nanocarriers mass is constituted by Compritol ${ }^{\circledR} 888$ ATO. Moreover, Compritol $^{\circledR} 888$ ATO spectrum has a defined band at $1175 \mathrm{~cm}^{-1}$ representing the stretching of C-O ester bonds. In the SLN-SC and NLC-SC spectra, this band is broader (indicating more bonds of this type), and is shifted to lower values (to $1107 \mathrm{~cm}^{-1}$ and $1109 \mathrm{~cm}^{-1}$ for SLN-SC and NLCSC, respectively), indicating weakening of these bonds. This happens due to the fact that Compritol ${ }^{\circledR} 888$ ATO is no longer in its bulk form, but now in nanostructures. In the form of SLN and NLC, Compritol ${ }^{\circledR} 888$ ATO crystals have a bigger surface area than in the bulk form (explaining the broadening of the peak) and are less agglomerated (explaining the shift in the wavenumbers). The nonexistence of any new absorption bands in the FTIR spectra of SLN-SC and NLC-SC is an indicative of the absence of interactions and incompatibilities between the lipid and SC.

Regarding the DSC analyses (Figure 5), the Compritol $^{\circledR} 888$ ATO melting peak is sharper than the SLN-SC and NLC-SC ones, which indicates that the bulk material is more crystalline than the nanostructures. This was already shown by SAXS curves (Figure 3(A)). The broader peak for the NLC-SC compared to the one observed for SLN-SC suggests a more unstructured lipid matrix for NLC formulation (Carbone et al., 2014). This may be attributed to the imperfections of the lipid matrix of NLC, generated by the presence of peanut oil. The more unstructured lipid matrix of NLC-SC can have an impact on the encapsulation of SC.

The improved ability to encapsulate SC in NLCSC over SLN-SC was confirmed by PLM (Figure 6). SC crystals were observed for SLN-SC, while they were not visualised for NLC-SC. SC is a crystalline and very lipophilic molecule, therefore, if it were not loaded in the nanoparticle, it would be clearly visualised by PLM. Patel et al. (2010) developed SC-loaded liposomes and $\mathrm{SC}$ encapsulation was evaluated only by the absence of precipitation in the formulation.

The lipid matrix imperfections allow better accommodation of the drug in NLC compared to SLN and these findings are in line with previously described data (Fang et al., 2013; Beloqui et al., 2016; Pan et al., 2016). This improved drug loading capacity is one of the main reasons for the advent of NLC over SLN in the last decade. Therefore, NLC-SC was selected for further studies of cell viability and cell cycle evaluations.

In the cell viability studies (Figure 7), Blank-NLC did not show any toxicity with the concentration range used. Such non-toxic behaviour is widely described for blank SLN and blank NLC due to the safe nature of their constituent materials (Doktorovova et al., 2014). Free SC and NLC-SC showed a similar high cytotoxicity for a wide SC concentration range (up to $30 \mu \mathrm{M}$ SC in the case of MDA-MB-231 and up to $15 \mu \mathrm{M}$ SC in the case of HCT-116). However, $\mathrm{IC}_{50}$ values for free $\mathrm{SC}$ were lower than those for NLC-SC in both cell lines. These findings are in line with previously published data which showed that free SC cytotoxicity was higher than that observed for SC-loaded liposomes (Hatziantoniou et al., 2006; Mahaira et al., 2011). It was shown that when SC was loaded in liposomes, a lower cytosol (where it is believed SC has its site of action) concentration was achieved compared to free SC due to a different intracellular distribution (Paradissis et al., 2007a, 2007b). We can assume that a similar phenomenon could have happened for NLC-SC.

Free SC generated an increase in subdiploid DNA content. The presence of subdiploid DNA content in cell cycle experiments following SC treatment has been previously reported by other studies with some cancer cell lines (HCT-116, MCF-7, and MOLT-3) (Dimas et al., 1999, 2001, 2006; Mahaira et al., 2011). Subdiploid DNA content is generally an indicative of a cell death process by apoptosis (Pan et al., 2016). This is consistent with previous works that showed that SC generated cell death by this mechanism (Dimas et al., 1999, 2007; Darzynkiewicz et al., 2010; Mahaira et al., 2011).

However, NLC-SC showed a different behaviour from that observed for free SC (Figure 8(A) and 8(B)). While NLC-SC produced an impressive increase in subdiploid DNA content in the MDA-MB-231 cell line, it produced a $\mathrm{G}_{2} / \mathrm{M}$ cell cycle arrest in the HCT-116 cell line. While the generation of subdiploid DNA content by $\mathrm{SC}$ has been well described, $\mathrm{G}_{2} / \mathrm{M}$ arrest has not yet been reported after an $\mathrm{SC}$ treatment. The $\mathrm{G}_{2} / \mathrm{M}$ cell cycle arrest has been reported for several drugs currently used in oncology clinics such as doxorubicin (Golunski et al., 2016), paclitaxel (Han, Le, 2016), cisplatin(Voland et al., 2006) and etoposide (Nam et al., 2010). For all of these drugs, $\mathrm{G}_{2} / \mathrm{M}$ arrest is linked to cell death by apoptosis. The $\mathrm{G}_{2} / \mathrm{M}$ arrest, however, has also been reported as an indicative of cell death by autophagy (Lambert et al., 2008; Filippi-Chiela et al., 2011). Although, no study has 
shown that SC produced cell death by autophagy, Shakeelu-Rehman et al. (2015) showed that an SC derivative led to cell death in the PC-3 (human prostate cancer) cell line by this mechanism.

Panzarini et al. (2013) emphasise that nanoparticles can stimulate autophagy processes. Thus, the question arises whether this distinct behaviour, seen for HCT116 cells when treated with NLC-SC would probably be due to apoptosis or a new mechanism of cell death, like autophagy. In that way, it shows, as a perspective for this work, the performance of cell death mechanisms assays. Therefore, the encapsulation of SC in NLC alters its biological properties, slightly reducing its cytotoxicity and altering the cell cycle patterns.

Nevertheless, it is essential to look at the in vivo limitations of SC. When it was administered in its free form in mice, it could not produce antitumour effects unless very high doses were used, which has led to several side effects (Hatziantoniou et al., 2006). SC encapsulation in nanocarriers made its in vivo administration possible (Hatziantoniou et al., 2006; Dimas et al., 2007; Mahaira et al., 2011) and, in that way, NLC-SC presents itself as a novel nanocarrier for SC encapsulation with all the aforementioned benefits that NLC can provide.

\section{CONCLUSION}

This work has shown that it is possible to load SC in NLC, formulating nanocarriers with small size, narrow size distribution, and efficient SC encapsulation. It has been shown that NLC can load SC in a more efficient way than SLN, probably due to a more unstructured lipid matrix. These results show the benefits of NLC as a novel nanocarrier to deliver hydrophobic drugs.

NLC-SC showed to be slightly less cytotoxic than free $\mathrm{SC}$ in both evaluated cell lines and to evoke $\mathrm{G}_{2} / \mathrm{M}$ cell cycle arrest in the HCT-116 cell line. This shows that the encapsulation of $\mathrm{SC}$ alters its biological properties in vitro as already shown by other works. Notwithstanding, NLCSC represents a novel nanocarrier to load SC, making possible its administration in vivo.

\section{ACKNOWLEDGMENTS}

The authors would like to acknowledge the LNLS Synchrotron (Campinas, Brazil) for the use of SAXS-1 beamline. The authors also wish to thank Glenn Hawes (ret.) from the American Language Program of the University of Georgia for editing this manuscript.

\section{FINANCIAL AND COMPETING INTEREST DISCLOSURE}

This work was supported by NIH under grant 1R03TW008709; by Minas Gerais State Agency for Research and Development (FAPEMIG, Brazil) and by the Brazilian agencies CAPES and CNPq. The authors have no other relevant affiliations or financial involvement with any organization or entity with a financial interest in or financial conflict with the subject matter or materials discussed in the manuscript apart from those disclosed. The authors state that they have no conflicts of interest and have received no payment in preparation of this manuscript. All authors have approved the final article.

\section{REFERENCES}

Akanda MH, Rai R, Slipper IJ, Chowdhry BZ, Lamprou D, Getti G et al. Delivery of retinoic acid to LNCap human prostate cancer cells using solid lipid nanoparticles. Int J Pharm. 2015;493(1-2):161-171.

Atasanov AG, Waltenberger B, Pferschy-Wenzig, Linder T, Wawrosch C, Uhrin P et al. Discovery and ressuply of pharmacologically active plant derived natural Products: a review. Biotechnol Adv. 2015;33(8):1582-1614.

Bayón-Cordero L, Alkorta I, Arana L. Application of solid lipid nanoparticles to improve the efficiency of anticancer drugs. Nanomaterials. 2019;9(3):E474.

Beloqui A, Solinís MA, Rodríguez-Gascón A, Almeida AJ, Préat V. Nanostructured lipid carriers: promising drug delivery systems for future clinics. Nanomedicine. 2016;12:143-161.

Benita S, Levy MY. Submicron emulsions as colloidal drug carriers for intravenous administration: comprehensive physicochemical characterization. J Pharm Sci. 1993;82(11):1069-1079.

Carbone C, Campisi A, Musumeci T, Raciti G, Bonfanti R, Puglisi G. FA-loaded lipid drug delivery systems: Preparation, characterization and biological studies. Eur J Pharm Sci. 2014;52:12-20.

Carneiro G, Silva EL, Pacheco LA, Souza-Fagundes EM, Corrêa NCR, GOES AM et al. Formation of ion pairing as an alternative to improve encapsulation and anticancer activity of all-trans retinoic acid loaded in solid lipid nanoparticles. Int J Nanomedicine. 2012;7:6011-6020. 
Castro GA, Coelho ALLR, Oliveira CA, Mahecha GA, Oréfice RL, Ferreira LA. Formation of ion pairing as an alternative to improve encapsulation and stability and to reduce skin irritation of retinoic acid loaded in solid lipid nanoparticles. Int J Pharm. 2009;381:77-83.

Darzynkiewicz Z, Halicka HD, Zhao H. Analysis of cellular DNA content by flow and laser scanning cytometry. Adv Exp Med Biol. 2010;676:137-147.

Dimas K, Kokkinopoulos, Demetzos C, Vaos B, Marselos M, Malamas $\mathrm{M}$ et al. The Effect of sclareol on growth and cell cycle progression of human leukemic cell lines. Leuk Res. 1999;23(3):217-234.

Dimas K, Demetzos C, Vaos V, Ioannidis P, Trangas T. Labdene type diterpenes down-regulate the expression of $c$-myc protein, but not of $b c l-2$ in human leukemia T-cells undergoing apoptosis. Leuk Res. 2001;25(6):449-454.

Dimas K, Papadaki M, Tsimplouli C, Hatziantoniou S, Alevizopoulos K, Pantazis P et al. Labd-14-ene-8,13-diol (sclareol) induces cell cycle arrest and apoptosis in human breast cancer and enhances the activity of anticancer drugs. Biomed Pharmacother. 2006;60(3):127-133.

Dimas K, Hatziantoniou S, Tseleni S, Khan H, Georgopoulos A, Alevizopoulos $\mathrm{K}$ et al. Sclareol induces apoptosis in human HCT116 colon cancer cells in vitro and suppression of HCT116 tumor growth in immunodeficient mice. Apoptosis. 2007;12(4):685-694.

Doktorovova S, Souto EB, Silva AM. Nanotoxicology applied to solid lipid nanoparticles and nanostructured lipid carriersa systematic review of in vitro data. Eur J Pharm Biopharm. 2014;87:1-18.

Ebenstein Y, Nahum E, Banin, U. Tapping Mode Atomic Force Microscopy for Nanoparticle Sizing: Tip-Sample Interaction Effects. Nano Lett. 2002;2(9):945-950.

Fang C, Al-Suwayehb SA, Fang JY. Nanostructured lipid carriers (NLCs) for drug delivery and targeting. Recents Pat Nanotechnol. 2013;7(1):41-55.

Filippi-Chiela EC, Villodre ES, Zamin LL, Lenz G. Autophagy interplay with apoptosis and cell cycle regulation in the growth inhibiting effect of resveratrol in glioma cells. PLoS One. 2011;6(6):1-23.

Golunski G, Borowik A, Derewonko N, Kawiak A, Rychlowski M, Woziwodzka A, et al. Pentoxifylline as a modulator of anticancer drug doxorubicin. Part II: reduction of doxorubicin DNA binding and alleviation of its biological effects. Biochimie. 2016;123:95-102.
Han B, Le M. Paclitaxel-induced G2/M arrest via different mechanism of actions in glioma cell Lines with differing p53 mutational status. Inter J Pharmacol. 2016;12(1):19-27.

Hatziantoniou S, Dimas K, Georgopoulos A, Sotiriadou N, Demezos C. Cytotoxic and antitumor activity of liposomeincorporated sclareol against cancer cell lines and human colon cancer xenografts. Pharmacol Res. 2006;53(1):80-87.

Hsieh YH, Deng JS, Pan HP, Liao JC, Huang SS, Huang GJ. Sclareol ameliorate lipopolysaccharide-induced acute lung injury through inhibition of MAPK and induction of HO-1 signaling. Int Immunopharmacol. 2017;44:16-25.

Jenning V, Thünemann AF, Gohla SH. Characterisation of a novel solid lipid nanoparticle carrier system based on binary mixtures of liquid and solid lipids. Int J Pharm. 2000a;199:167-177.

Jenning V, Mäder K, Gohla SH. Solid lipid nanoparticles (SLNTM) based on binary mixtures of liquid and solid lipids: a ${ }^{1}$ H-NMR study. Int J Pharm. 2000b;205:15-21.

Kalam MA, Sultana Y, Ali A, Aqil M, Mishra AK, Chuttani K. Preparation, characterization, and evaluation of gatifloxacin loaded solid lipid nanoparticles as colloidal ocular drug delivery system. J Drug Target. 2010;18(3):191-204.

Kalam MA, Sultana Y, Ali A, Aqil M, Mishra AK, Aljuffali IA et al. Part I: Development and optimization of solidlipid nanoparticles using Box-Behnken statistical design for ocular delivery of gatifloxacin. J Biomed Mater Res A. 2013;101(6):1813-1827.

Kuzma L, Skrzypek Z, Wysokinska H. Diterpenoids and triterpenoids in hairy roots of Salvia sclarea. Plant Cell Tissue Organ Cult. 2006;84:171-179.

Lambert LA, Qiao N, Hunt KK, Lambert DH, Mills GB, Meijer L et al. Autophagy: a novel mechanism of synergistic cytotoxicity between doxorubicin and roscovitine in sarcoma model. Cancer Res. 2008;68(19):7966-7974.

Li F, Wang Y, Liu Z, Lin X, He H, Tang X. Formulation and characterization of bufadienolides-loaded nanostructured lipid carriers. Drug Dev Ind Pharm. 2010;36(5):508-517.

Liu K, Sun J, Wang Y, He Y, Gao K, He Z. Preparation and characterization of 10-hydroxycamptothecin loaded nanostructured lipid carriers. Drug Dev Ind Pharm. 2008;34(5):465-471.

Lukowski G, Kasbohm J, Pflegel P, Iling A, Wulff, H. Crystallographic investigation of cetylpalmitate solid lipid nanoparticles. Int. J. Pharm. 2000; 196, 201-205. 
Mahaira LG, Tsimplouli C, Sakellaridis N, Alevizopoulos $\mathrm{K}$, Demetzos C, Han Z et al. The labdane diterpene sclareol (labd-14-ene-8, 13-diol) induces apoptosis in human tumor cell lines and suppression of tumor growth in vivo via a p53-independent mechanism of action. Eur J Pharmacol. 2011;666:173-182.Marquele-Oliveira F, Santana DCA, Taveira SF, Vermeulen DM, Oliveira ARM, Silva RS et al. Development of nitrosyl ruthenium complex-loaded lipid carriers for topical administration: improvement in skin stability and in nitric oxide release by visible light irradiation. J Pharm Biomed Anal. 2010;53(4):843-851.

Mazzaferro S, Bouchemal K, Ponchel G. Oral delivery of anticancer drugs I: general considerations. Drug Discov Today. 2013;18(1-2):25-34.

Nahak P, Karmakar G, Chettri P, Roy B, Guha P, Besra SE et al. Influence of Lipid Core Material on Physicochemical Characteristics of Ursolic Acid Loaded Nanostructured Lipid Carrier: An Attempt to Enhance Anticancer Activity. Langmuir. 2016;32(38):9816-9825.

Nam C, Doi K, Nakayama H. Etoposide induces G2/M arrest and apoptosis in neural progenitor cells via DNA damage and an ATM/p53-related pathway. Histol Histopathol. 2010;25:485-493.

Nicoletti I, Migliorati G, Pagliacci MC, Grignani F, Riccardi C. A rapid and simple method for measuring thymocyte apoptosis by propidium iodide staining and flow cytometry. $\mathrm{J}$ Immunol Methods. 1991;139(2):271-279.

Noori D, Hassan ZM, Mohammadi M, Habibi Z, Sohrabi N, Bayanolhagh S. Sclareol modulates the Treg intra-tumoral infiltrated cell and inhibits tumor growth in vivo. Cell Immunol. 2010;263:148-153.

Pan Y, Tikekar RV, Nitin N. Distribution of a model bioactive within solid lipid nanoparticles and nanostructured lipid carriers influences its loading efficiency and oxidative stability. Int J Pharm. 2016;511(1):322-330.

Panzarini E, Inguscio V, Tenuzzo BA, Carata E, Dini L. Nanomaterials and autophagy: new insights in cancer treatment. Cancers. 2013;5:296-319.

Paradissis A, Hatziantoniou S, Georgopoulos A, Psarra AM, Dimas K, Demetzos C. Liposomes modify the subcellular distribution of sclareol uptake by HCT-116 cancer cell lines. Biomed Pharmacother. 2007a;61:120-124.

Paradissis A, Hatziantoniou S, Georgopoulos A, Dimas K, Demetzos C. Uptake studies of free and liposomal sclareol by MCF-7 and H-460 human cancer cell lines. In: Mozafari MR, editor. Nanomaterials and Nanosystems for Biomedical Applications. 1st ed. Dordrecht: Springer; 2007b. p. 125-133.
Patel N.R, Hatziantoniou S, Georgopoulos A, Demetzos C, Torchilin VP, Weissig V et al. Mitochondria-targeted liposomes improve the apoptotic and cytotoxic action of sclareol. J Liposome Res. 2010;20(3):244-249.

Patil-Gadhe A, Kyadarkunte A, Patole M, Pokharkar V. Montelukast-loaded nanostructured lipid carrier: Part II pulmonary drug delivery and in vitro-in vivo aerosol performance. Eur J Pharm Biopharm. 2014;88(1):169-177.

Shakeel-u-Rehman, Rah B, Lone SH, Rasool RU, Farooq $\mathrm{S}$, Nayak D et al. Design and synthesis of antitumor heckcoupled sclareol analogues: modulation of $\mathrm{BH} 3$ family members by SS-12 in autophagy and apoptotic cell death. J Med Chem. 2015;58(8):3432-3444.

Seo S, Gomi K, Kaku, H, Abe H, Seto H, Nakatsu S et al. Identification of natural diterpenes that inhibit bacterial wilt disease in tobacco, tomato and arabidopsis. Plant Cell Physiol. 2012;53(8):1432-1444.

Silva EL, Carneiro G, Caetano PA, Goulart G, Costa DF, Souza-Fagundes EM et al. Nanostructured lipid carriers loaded with tributyrin as an alternative to improve anticancer activity of all-trans retinoic acid. Expert Rev Anticancer Ther. 2015;15(2):247-256.

Silva EL, Lima FA, Carneiro G, Ramos JP, Gomes DA, SouzaFagundes EM et al. Improved in vitro antileukemic activity of all-trans retinoic acid loaded in cholesteryl butyrate solid lipid nanoparticles. J Nanosci Nanotechnol. 2016;16:12911300.Taurin S, Nehoff H, Greish K. Anticancer nanomedicine and tumor vascular permeability: where is the missing link? J Control Release. 2012;164:265-275.

USP. <729> Globule size distribution in lipid injectable emulsions. The United States Pharmacopeia 33. 2009. pp. 314-316.

Voland C, Bord A, Péleraux A, Pénarier G, Carrière D, Galiègue $\mathrm{S}$ et al. Repression of cell cycle-related proteins by oxaliplatin but not cisplatin in human colon cancer cells. Mol Cancer Ther. 2006;5(9):2149-2157.

Wang J, Wang H, Zhou X, Tang Z, Liu G, Liu G et al. Physicochemical characterization, photo-stability and cytotoxicity of coenzyme Q10-loading nanostructured lipid carrier. J Nanosci Nanotechnol. 2012;12:2136-2148.

Wong HL, Benadayan R, Rauth AM, Li Y, Wu XY. Chemotherapy with anticancer drugs encapsulated in solid lipid nanoparticles. Adv Drug Deliv Rev. 2007;59:491-504.

Received for publication on $07^{\text {th }}$ August 2018 Accepted for publication on $15^{\text {th }}$ December 2019 